\title{
Adaptação à Creche e o Processo de Separação-Individuação: Reações dos Bebês e Sentimentos Parentais
}

\author{
Tatiele Jacques Bossi \\ Elenice Soares \\ Rita de Cássia Sobreira Lopes \\ Cesar Augusto Piccinini \\ Universidade Federal do Rio Grande do Sul \\ Porto Alegre, RS, Brasil
}

\begin{abstract}
RESUMO
Este estudo investigou os relatos das mães e pais sobre as reações dos bebês frente à adaptação à creche e os sentimentos e reações parentais. Participaram 13 bebês e seus genitores que ingressaram na creche durante as subfases do processo de separação-individuação: diferenciação ( $6^{\circ}$ mês), exploração ( $12^{\circ}$ mês) e reaproximação ( $20^{\circ}$ mês). Análise de conteúdo qualitativa das entrevistas apontou que reações de recusa à alimentação e adoecimento fizeramse particularmente presentes entre os bebês que estavam nas subfases de diferenciação e exploração. Sentimentos de insegurança predominaram no relato dos genitores cujos bebês estavam na subfase de exploração, quando alguns não conseguiram se adaptar à creche. Na subfase de reaproximação, apesar das reações iniciais da criança e de sentimentos de insegurança parentais, os bebês apresentaram boa adaptação. Destaca-se a importância da presença parental no período de adaptação, contribuindo para que a creche torne-se uma referência para o bebê possibilitando a continuidade do processo de separação-individuação.
\end{abstract}

Palavras-chaves: Creche; adaptação à creche; processo de separação-individuação.

\section{ABSTRACT}

The Adjustment to Daycare Center and Separation-Individuation Process: Infants'Reactions and Parents' Feelings The present research investigated the reports of mothers and fathers about the babies' reactions during the daycare adjustment and also the parents' feelings and reactions at this moment. Thirteen babies and their parents who entered a daycare center during the differentiation (6th month), practicing (12th month) and rapprochement (20th month) sub-phases of the Separation-Individuation Process, took part in the study. Content analysis revealed that the feed refuse and illness were babies' reactions in the differentiation and practicing sub-phases. Insecurity feelings were more frequent in the parents whose babies were in the practicing sub-phases, when some did not adjust to the daycare. In the rapprochement sub-phase the babies showed good adjustment despite babies' initial reactions and some parents' feelings of insecurity. The study highlights that the parents' presence in the adjustment period makes the daycare center a landmark for the baby that permits the continuity of the separation-individuation process.

Keywords: Daycare center; daycare adjustment; separation-individuation process.

\section{RESUMEN}

Adaptación a lo Jardin Infantil y el Proceso de Separacion-Individualizacion: Reacciones de los Bebés y Sentimientos de los Padres

Este estudio investigó los informes de las madres y padres sobre las reacciones de los bebés en la adaptación al jardín infantil y los sentimientos y reacciones parentales en este momento. Participaron 13 niños y sus padres que entraron en el jardín infantil durante las subfases del proceso de separación-individualización: diferenciación ( $6^{\circ}$ mes), exploración (12을 mes) y reaproximación $\left(20^{\circ} \mathrm{mes}\right)$. El análisis de contenido cualitativo de las entrevistas mostró que reacciones negativas a los alimentos y las enfermedades estaban especialmente presentes entre niños que se encontraban en las subfases de diferenciación y exploración. Sentimientos de inseguridad fueron más frecuentes en los padres cuyos bebés estaban en la subfase de exploración, cuando algunos no han sabido adaptarse a lo jardín infantil. En la subfase de reaproximación, a pesar de las reacciones iniciales del niño y sentimientos de inseguridad de los padres, los bebés mostraron una buena adaptación. El estudio resalta la importancia de la presencia parental durante la adaptación, contribuyendo para que el jardín infantil se convierta en una referencia para el niño permitiendo la continuidad del proceso de separación-individualización.

Palabras clave: Jardín infantil; adaptación al jardín infantil; proceso de separación-individualización. 
O processo de separação-individuação (Mahler, Pine, \& Bergman, 1977), envolve dois aspectos inter-relacionados, sendo a separação que se refere à saída do bebê da fusão simbiótica estabelecida com a mãe; e a individuação que é marcada por aquisições que permitem à criança ir assumido suas próprias características. Trata-se de um processo que ocorre na presença e disponibilidade emocional da mãe ou outra figura afetiva, e se opõe a situações traumáticas de separação. Por volta dos quatro meses do bebê começaria o processo de separaçãoindividuação em suas quatro subfases (Mahler, et al., 1977): diferenciação, exploração, reaproximação, e consolidação da individuação e constância de objeto emocional. No entanto, para o presente estudo, devido à idade dos bebês investigados (quatro a 21 meses), serão destacadas apenas as três primeiras subfases que são caracterizadas a seguir.

A subfase de diferenciação inicia por volta do quarto mês de vida e tem como principal característica a diminuição, por parte do bebê, da dependência corporal da mãe, que até então era total. O desenvolvimento motor permite ao bebê ter firmeza de tronco tornando-o capaz de se distanciar corporalmente da mãe e, assim, reconhecê-la tátil e visualmente como uma parceira na simbiose e não como parte de seu corpo. Conforme Mahler, et al. (1977) o bebê, ao admirar-se com as características do rosto da mãe, passa a compará-lo com a face de outros adultos com que venha a ter contato. Se a simbiose ocorrer adequadamente e o bebê desenvolver o "sentimento de confiança básica" (Erikson, 1972), ele volta-se com maior curiosidade para o exame dos estranhos. Do contrário, se a simbiose não possibilitou a confiança básica, o exame de outros adultos que não a mãe pode se transformar em ansiedade aguda com relação a estranhos.

A segunda subfase, denominada exploração, tem início por volta dos dez meses do bebê (Mahler, et al., 1977). Ocorre uma expansão das capacidades motoras (engatinhar, arrastar-se e caminhar) e da exploração do ambiente ao redor, seja ele humano ou inanimado. Segundo os autores a principal característica dessa subfase é o envolvimento narcisista do bebê em suas habilidades e na investigação do ambiente ao redor. Isso permite que ele se aventure para mais longe da mãe e fique absorto em suas atividades, parecendo esquecê-la momentaneamente. No entanto, de tempos em tempos, retorna à figura materna para receber o que Mahler, et al. (1977) chamou de "reabastecimento emocional", adquirido através do contato físico com a mãe.

A terceira subfase, denominada reaproximação, tem início por volta dos 17 meses, quando o bebê torna-se mais seguro na sua capacidade de caminhar, e, consequentemente, dedica menor investimento de catexia na capacidade motora (Mahler, et al., 1977). A locomoção indica ao bebê que ele está autorizado a separar-se da mãe e, tal fato, provoca certo grau de ansiedade de separação. Da mesma forma, a catexia passa a ser redistribuída e dirigida a outros objetos ao seu redor permitindo que o esquecimento da figura materna, característico da subfase anterior, seja substituído pela necessidade de uma reaproximação com ela. Nessa subfase, ao contrário da anterior, os adultos familiares não são facilmente aceitos como substitutos da mãe (Mahler, et al., 1977).

Vale ressaltar que o processo de separação-individuação, além de se constituir em uma importante conquista da criança, está relacionado ao desenvolvimento da própria parentalidade, que também envolve passar por um processo de separação-individuação na fase adulta, agora com uma estruturação psíquica mais elaborada (Colarusso, 1990). Para Colarusso (1990) há uma ressignificação da relação que os novos pais estabeleciam com os seus próprios pais, bem como o retorno psíquico dos resquícios de seu processo de separação-individuação infantil. Tais aspectos repercutem na relação dos pais com o seu bebê, já que, diferentemente da sua infância em que eles eram os bebês frágeis que necessitavam dos cuidados de um adulto, agora eles são os adultos que tem a capacidade de cuidar de um frágil bebê. Isso permite perceber que o processo de separação-individuação do filho não se dá de forma simples, mas sim imerso a muita complexidade de significados, por envolver o mundo psíquico do bebê, da mãe e do pai.

Um aspecto importante de ser mencionado é que a teoria do processo de separação-individuação foi elaborada com base nos estudos de bebês que eram cuidados exclusivamente pelas mães, não tendo investigado o contexto dos cuidados alternativos. O presente estudo é uma tentativa de ampliar os achados existentes ao abordar o contexto de adaptação do bebê e dos genitores a situação de creche. Sabe-se que não há um consenso na literatura quanto à definição de adaptação. Para Vitória e Rossetti-Ferreira (1993) o período de adaptação à creche é o momento que dura em torno de um mês desde o ingresso do bebê na creche, mas pode estender-se por mais tempo, completando-se quando o bebê e as educadoras forem capazes de interagir de maneira mais descontraída na instituição. As autoras também destacaram que para cada bebê a adaptação ocorre de forma singular, já que o modo como os envolvidos vivenciam a adaptação influenciará o bebê, assim como será influenciado por ele. Isso também é enfatizado no referencial curricular para a educação infantil (Brasil, 1998), que destaca 
que o tempo de adaptação é variável para cada bebê, e isso precisa ser respeitado. Apesar das divergências em torno do conceito de adaptação, já existe certo consenso de que os primeiros dias do bebê na creche devem ser tratados como um momento especial e decisivo para sua permanência na educação infantil. Para muitos bebês, a entrada na creche representa a primeira experiência de cuidado não materno regular (Santos \& Moura, 2002) necessitando, como em qualquer cuidado alternativo, de um período de adaptação (Amorim, Vitória, \& Rossetti-Ferreira, 2000; Rapoport \& Piccinini, 2004), que para muitos bebês e genitores pode ser bastante complexo.

Em um estudo com 41 educadoras (21 atendiam bebês entre 4-5 meses e 20 atendiam bebês entre 8-9 meses), Rapoport e Piccinini (2001) destacaram como aspectos importantes na adaptação do bebê, independente da faixa etária, a demonstração de afeto, a atenção individualizada às necessidades do bebê e a continuidade com o lar dele, através da presença de um dos genitores, para que a inserção ocorra de maneira gradual e a creche não se torne uma referência muito distante do que o bebê é acostumado em seu lar. Contudo as educadoras destacaram como prática mais comum no período de adaptação os horários reduzidos de permanência do bebê, e menos comum a presença de um familiar, seja na sala com ele ou em outro ambiente da creche.

No entanto, apesar de pesquisadores já refletirem a algumas décadas sobre essa temática, percebe-se escassez de estudos cujo foco seja a adaptação dos bebês à creche no primeiro ano de vida. Os estudos que tem como temática a educação infantil destacam temas envolvendo a família e a creche (Maranhão \& Sarti, 2007; Maranhão \& Sarti, 2008), as interações dos bebês entre si (Schmitt, 2008; Sestini, 2008), as interações com as educadoras (Amorim, Vitoria, \& Rossetti-Ferreira, 2000; Schmitt, 2008; Mariotto, 2009; Dias, 2010), além de abordar o desenvolvimento em termos cognitivo (Lordelo, Chalhub, Guirra, \& Carvalho, 2007; Albers, Riksen-Walraven, \& Weerth, 2010; Murta, Lessa, Santos, Murta, \& Cambraia, 2011), motor (Baltieri, et al., 2010; Murta, et al., 2011), social (Murta, et al., 2011) e de desenvolvimento da linguagem (Majorano, Cigala, \& Corsano, 2009; Ramos, 2010; Murta, et al., 2011). Poucos estudos abordam o processo de adaptação dos bebês à creche e os que o fazem (Davies \& Brember, 1991; Vitória \& Rossetti-Ferreira,1993; Rapoport, 1999; Rapoport \& Piccinini, 2004) destacam aspectos relativos às semelhanças e particularidades na adaptação de bebês em diferentes faixas etárias, com base no relato das educadoras (Rapoport \& Piccinini, 2001) ou através de observação dos bebês e entrevistas com educadoras e mães visando investigar as estratégias de enfrentamento do bebê à adaptação à creche (Rapoport, 1999). Também investigam os bebês antes e após a entrada na creche (adaptação até cinco meses após o ingresso na creche) com o objetivo de conhecer a associação entre apego mãe-bebê, emoções negativas do bebê e elevação dos níveis de cortisol durante a transição para a creche, destacando o momento de separação da mãe como extremamente estressante para os bebês (Ahnert, Gunnar, Lamb, \& Barthel, 2004). Destaque para o envolvimento paterno na etapa de transição para a creche (Gabriel, 2012) e os sentimentos maternos durante a adaptação do filho à creche (Ferreira, 2007) ainda apresentam-se de maneira escassa na literatura.

Por exemplo, o estudo realizado por Ferreira (2007) com quatro mães de bebês que ingressaram na creche entre as idades de 12 a 28 meses destacou os sentimentos maternos durante esse período. Os mais comuns foram preocupação e desconfiança frente aos cuidados dispensados pelas educadoras, preocupações com relação ao choro do bebê que acabava desencadeando ansiedade nas mães, e sentimentos de ambivalência, já que ora confiavam e ora desconfiavam dos cuidados na creche. No entanto, as mães mencionaram como positiva a experiência dos filhos, já que a creche lhes possibilitava o aprendizado, o estabelecimento de uma rotina e a socialização.

Dessa forma, o presente estudo teve por objetivo investigar a adaptação de bebês à creche em diferentes momentos de ingresso à instituição. As idades dos bebês que participaram do estudo representam as subfases do processo de separação-individuação (Mahler, et al., 1977), a saber, diferenciação, exploração, e reaproximação. Em cada uma dessas subfases foram investigados os relatos das mães e pais sobre as reações do bebê durante o período de adaptação à creche, bem como os sentimentos e reações parentais a esse momento.

\section{MÉTODO}

\section{Participantes}

Participaram do presente estudo 13 bebês e seus genitores, sendo que seis bebês ingressaram na creche com idades entre quatro a sete meses (subfase de diferenciação); quatro bebês com idades entre dez a 15 meses (subfase de exploração); e três bebês com idades entre 19 a 21 meses (subfase de reaproximação). As mães tinham idades entre 20 e 31 anos, e escolaridade que variou de ensino fundamental incompleto a superior completo. Os pais tinham idades entre 19 e 39 anos e escolaridade que variou de ensino fundamental incompleto a superior incompleto. Quanto ao estado 
civil todos se declararam casados ou em união estável sendo que os bebês eram o primeiro filho dos casais.

Todos os participantes foram selecionados entre os integrantes do projeto "Estudo longitudinal de Porto Alegre: da gestação à escola - ELPA" (Piccinini, Tudge, Lopes, \& Sperb, 1998), que iniciou acompanhando 81 famílias que esperavam o primeiro filho, estendendo-se por várias fases de coleta de dados, até a entrada da criança na escola (gestação, $3^{\circ}, 8^{\circ}, 12^{\circ}, 18^{\circ}, 24^{\circ}$ e $30^{\circ}$ meses e $6^{\circ}$ e $7^{\circ}$ anos da criança). O projeto teve por objetivo investigar tanto os aspectos subjetivos e comportamentais das interações iniciais pai-mãe-bebê, assim como o impacto de fatores iniciais do desenvolvimento nas interações familiares, no comportamento social de crianças pré-escolares e na transição para a escola de ensino fundamental. O ELPA foi aprovado pelo Comitê de Ética da Universidade Federal do Rio Grande do Sul e os participantes assinaram o Termo de Consentimento Livre e Esclarecido.

\section{Delineamento, procedimento e instrumentos}

Foi utilizado o delineamento de estudo de caso coletivo (Stake, 1994) considerando as três subfases do processo de separação-individuação: diferenciação, exploração e reaproximação. O processo de adaptação dos bebês à creche foi investigado a partir da "Entrevista sobre a experiência da maternidade e desenvolvimento do bebê" (GIDEP, 1998a) e da "Entrevista sobre a experiência da paternidade e desenvolvimento do bebê" (GIDEP, 1998b). Essas entrevistas estruturadas eram compostas de diversos temas relacionados à experiência da maternidade e paternidade, ao desenvolvimento infantil e sobre a participação de outros cuidadores e da creche. Para fins de análise do presente estudo foram particularmente examinadas as questões que versavam sobre a adaptação do bebê à creche, bem como os sentimentos e reações da mãe, do pai e do bebê ao novo contexto. O momento de realização da entrevista variou entre os casos levando em consideração a idade de entrada do bebê na creche e se baseou nos relatos dos genitores sobre a adaptação, já que as entrevistas foram realizadas entre três a cinco meses após a entrada do bebê na creche. Além das entrevistas com a mãe e o pai foram considerados para análise dados oriundos da "Ficha de dados demográficos da família" (GIDEP, 1998c), aplicada no momento inicial do estudo, que permitiram caracterizar os participantes.

\section{RESULTADOS}

Os dados foram submetidos à análise de conteúdo qualitativa (Bardin, 1977; Laville \& Dionne, 1999), na qual foram consideradas três categorias de análise representando as subfases do processo de separaçãoindividuação (Mahler, et al., 1977): diferenciação, exploração e reaproximação. Dentro de cada categoria foram investigadas as reações do bebê frente à adaptação à creche e os sentimentos e reações parentais frente à adaptação do bebê. Apresenta-se a seguir a caracterização de cada categoria, ilustrando-as com os relatos dos genitores.

\section{Subfase de diferenciação (4 a 9 meses)}

Nessa subfase do processo de separação-individuação (Mahler, et al., 1977) o bebê mostra-se curioso com o familiar (mãe) e o não familiar (outras pessoas e ambientes desconhecidos). Dessa forma, pode-se pensar que o bebê inserido na creche nesse período poderá apresentar algumas particularidades no seu comportamento, como humor instável durante os momentos em que se encontra na creche sem a presença da mãe, desinteresse nas atividades propostas pelas educadoras e até apatia, dentre outros comportamentos. Já com a presença materna ou de outra figura afetiva o bebê tenderia a ter interesse na interação com o ambiente. Os casos apresentados a seguir, referentes a seis bebês que ingressaram na creche durante a subfase de diferenciação, apresentam algumas evidências sobre essa subfase.

Um dos bebês (B1/menina) $)^{1}$ que ingressou na creche aos quatro meses, apresentou uma adaptação "difícil", já que ela mamava no peito e não havia sido inserida na alimentação sólida: "Foi super difícil a adaptação para ela, porque ela só queria o seio, né?" (M1). Durante o período de adaptação a menina apresentou reações desesperadas de choro por vários dias, seguido de rejeição à alimentação na creche: "Então a rejeição que ela teve foi fazendo greve de fome, não comeu durante quinze dias, todo o tempo na creche sem comer" (M1). Frente a isso, a mãe, que havia iniciado a adaptação da filha à creche, não conseguiu finalizá-la por não suportar ver o sofrimento da menina. Ela também destacou ter ficado apreensiva, já que precisava retornar ao trabalho em poucos dias: "Aí, sabe de uma coisa, chegou um dia que eu ia trabalhar na sexta-feira, ela daquele jeito, larguei ela lá, eu disse, 'se ela chorar chamem o pai dela'" (M1). Naquele momento o pai se inseriu na creche, inclusive mostrando para as educadoras como amamentar a filha e, assim, facilitou a adaptação.

Reação de choro também se fez presente em outro bebê (B2/menino), que ingressou na creche aos seis

\footnotetext{
${ }^{1}$ Os participantes são identificados pelas letras B (bebê), M (mãe) e P (pai) seguido da respectiva numeração que os representa.
} 
meses. No entanto, o choro ocorreu durante curtos períodos de tempo e nos primeiros momentos de contato do bebê com a creche e as educadoras. Tal fato permitiu aos genitores destacarem que o filho teve uma adaptação rápida, conseguindo permanecer na creche desde o início sem maiores problemas: "Ele se adaptou super rápido na creche, foi um dos primeiros, assim, da turma, a ficar o tempo integral" (M2). Os genitores ressaltaram sentimentos de tranquilidade frente à entrada do filho na creche por saberem que ele estava em um espaço adequado para os cuidados de bebês. Para eles, por ter mais de uma educadora disponível, o cuidado em creche evitava a sobrecarga em apenas uma pessoa, como acontecia com o cuidado de uma babá ou de um familiar, por exemplo: "Ai quando ele foi para a creche foi mais tranquilo, porque eram mais pessoas, porque se uma [educadora] não aguentava mais, sei lá, passava para outra" (M2). Vale destacar que o pai trabalhava na creche em que o bebê foi inserido, tendo acompanhado o seu período de adaptação.

De modo semelhante, o terceiro bebê (B3/menino), que ingressou na creche aos sete meses, apresentou choro breve durante o período de adaptação, não manifestando outras reações já que se adaptou de forma rápida: "Ele dava uma choradinha, dai ela [a educadora] pegava alguma coisa que faz barulho e entregava para ele, ele se acalmava" (P3). O pai e a mãe manifestaram tranquilidade frente ao ingresso do filho à creche por saberem que ele estaria em um lugar que oferecia cuidados adequados. No entanto, o pai, que acompanhou a adaptação, destacou que não permanecia com o filho para evitar que ele chorasse por querer ficar somente no seu colo: "Mas na verdade eu nem ficava (...) nunca fiquei nem cinco minutos lá. Eu chego e entrego ele, agora ele não chora mais" (P3). Já a mãe mencionou que estranhou os primeiros dias do filho na creche, momento em que ela ainda não havia retomado as suas atividades (era estudante) e nem tinha o filho para ocupar seu tempo. Isso a fazia ter necessidade de buscar o filho na creche antes do horário estipulado para a adaptação. Ela também destacou que, por ficar chateada de deixar o filho chorando na creche não conseguia levá-lo, ficando essa responsabilidade para o pai. Vale destacar que essa mãe mencionou ter optado por colocar o filho na creche para que ela própria não ficasse tão "grudada" ao bebê evitando sofrimentos futuros de separação entre mãe e filho, sofrimentos esses vivenciados pela mãe em sua infância: "A minha intenção era que eu não ficasse tão grudada com ele, por isso que a gente optou pela creche. (...) então eu imagino que desde cedo assim, ele não vai ter aquele sofrimento de sair de casa" (M3).
Com relação ao quarto bebê (B4/menino), que ingressou na creche aos seis meses, os genitores destacaram, apenas, que ele se adaptou satisfatoriamente desde os momentos iniciais: "No segundo dia, o pessoal da creche já disse: 'pode ir embora que ele tá super adaptado," (P4). Mãe e pai manifestaram sentimentos de tranquilidade e segurança frente à entrada do filho na creche, por terem o entendimento de que os cuidados realizados por apenas uma pessoa eram mais cansativos: "Eu me senti super bem, porque eu fiquei bem mais tranquilo (...) que antes eu ficava assim, por causa que tinha essa babá, mas eu sei que é cansativo para uma pessoa só ficar" (P4).

Já outro bebê (B5/menino), que ingressou na creche aos sete meses, manifestou dificuldades em se distanciar das figuras parentais: "Ele não queria ficar com as tias na creche, mas depois ele ia, se tu dava um brinquedinho para ele, ele já ficava lá. Mas quando ele não via a gente, ele queria ir embora" (M5). Também o adoecimento se fez presente durante o período de adaptação, sendo que ele teve bronquite e infecção intestinal. No entanto, em oposição ao ressaltado nos casos anteriores, o pai e a mãe manifestaram insegurança por deixar o filho na creche, principalmente por não saberem como ele seria tratado pelas educadoras. Frente a isso, o pai ligava com frequência para a avó do menino, que acompanhou sua adaptação, para saber notícias do filho. Já a mãe mencionou preocupações quanto aos comportamentos manifestados pelo filho após a entrada na creche e o quanto isso poderia estar prejudicando o seu desenvolvimento: "Teve um dia que ele ficou doente, então ele tava tão sentido, só de tu falar mais alto ele já chorava. (...) agora ele fica todo sentido, e antes ele não ficava" (M5).

De modo semelhante, outro bebê (B6/menina), que ingressou na creche aos quatro meses, demonstrou dificuldades em se distanciar das figuras afetivas, no entanto tal fato não impediu que a adaptação ocorresse de forma rápida: "Quando ela tá mais carente, entre aspas, de alguém, ela não quer ir à creche (...) é eu que vou deixar ela lá, tu vê que ela não quer que saia de perto dela, mas ela se adapta bem" (P6). Mãe e pai destacaram que a adaptação foi mais difícil para eles do que para a filha ao ressaltarem o sofrimento por deixá-la na creche, seja por não terem desejado outras pessoas cuidando da menina, seja por sentirem que a mesma ficaria bem sem eles: "Tu sente aquela coisa assim, 'ela pode se virar sem mim'(...). Fica se sentindo meio de lado, 'ai, eu não sou uma boa mãe, to deixando a minha filha'" (M6).

Juntos, os relatos apresentados destacam alguns comportamentos dos bebês inseridos na creche durante a subfase de diferenciação do processo de separação- 
individuação (Mahler, et al., 1977). O choro foi o mais destacado, e ocorreu tanto durante breves momentos, como por vários dias durante o período de adaptação. A recusa à alimentação na creche, adoecimentos e dificuldades de se distanciar das figuras afetivas também foram destacados. Com isso, a adaptação foi considerada difícil em alguns casos, sendo que os genitores demonstraram insegurança por deixarem os filhos na creche. Já outros genitores consideraram que a adaptação transcorreu de maneira razoável nessa subfase. Em ambos os casos, a adaptação foi facilitada pela presença da mãe, do pai ou outra figura afetiva do bebê. O que vale ser ressaltado é que, para além da presença parental no período de adaptação, mostrou-se como importante a presença do genitor que demonstrava maior segurança e tranquilidade frente ao ingresso do filho à creche. Isso parece ter contribuído para a adaptação, mesmo nos casos mais difíceis, já que o bebê podia contar, em certa medida, com alguém que lhe servisse de suporte emocional nesse momento.

\section{Subfase de exploração (10 a 16 meses)}

Nessa subfase do processo de separação-individuação (Mahler, et al., 1977), o bebê mostra-se envolvido narcisicamente nas suas habilidades motoras em desenvolvimento. Dessa forma, pode-se pensar que o bebê inserido na creche durante essa subfase poderá apresentar algumas particularidades no seu comportamento, como interesse em conhecer o ambiente da creche, os outros bebês e as educadoras, e curiosidade frente às atividades propostas. Vale destacar que tal comportamento tenderá a ser manifesto de maneira mais expressiva quando a mãe ou outra figura de referência estiver disponível ao bebê na creche, possibilitando o reabastecimento emocional quando necessário. Os casos apresentados a seguir, referentes a quatro bebês que ingressaram na creche durante a subfase de exploração, apresentam algumas evidências sobre essa subfase.

Um dos bebês (B7/menina), que ingressou na creche aos 15 meses de idade, apresentou uma adaptação "horrivel" pelo fato de os primeiros dias terem sido difíceis já que ela estranhou o novo ambiente. Os genitores destacaram que a filha apresentou reações de choro no momento inicial na creche, acompanhado de adoecimento (gripe). Também destacaram que eles não suportavam o fato de a filha chorar nos primeiros dias na creche, o que fazia com que o pai deixasse de ir ao trabalho para levar a filha para casa: "Tinha vezes que eu não ia trabalhar, pegava ela, 'vamos embora para casa" "(P7). Questionamentos com relação ao bemestar da filha na creche também foram manifestados pelos genitores, já que o adoecimento da filha durante o período de adaptação fez com que eles considerassem que ela poderia não estar sendo bem cuidada: "Menos cuidados, não tava sendo bem cuidada como a gente queria que fosse né" (P7). Dessa forma, devido às dificuldades na adaptação, a menina não permaneceu na creche.

Aspectos semelhantes aos destacados acima ocorreram com outro bebê (B8/menino) que ingressou na creche aos dez meses de idade. Ele também não permaneceu na creche, sendo retirado durante o segundo mês na instituição. Os genitores relataram que o filho não conseguiu adaptar-se por não suportar estar longe das figuras parentais. Além de choro, o filho apresentou reações de agarrar-se à mãe ou pai no momento de ser entregue na creche. A recusa à alimentação também se fez presente, sendo que esse comportamento se apresentou após alguns dias em que o filho chorava na creche: "Quando eu ficava junto com ele na creche era o paraíso, né? Ele tinha brinquedo, tinha amiguinho, tinha tudo o que ele gostava (...) mas se eu não ficava, ai ele não comia nada a tarde inteirinha" (M8). O adoecimento do filho (gripe) também foi ressaltado como tendo ocorrido durante o período de adaptação. Frente a isso, o pai destacou sofrimento ao saber que o filho ficava chorando quando deixado na creche. Ele mencionou que no primeiro dia de adaptação a mãe não pode ficar com o bebê, o que o fez deixar o serviço na mesma hora em que foi avisado pela creche que o filho estava chorando: "No primeiro dia de creche que ele ficou sozinho [sem a mãe e chorou], eu tive que deixar a loja aberta sem ninguém, e sair correndo para buscar ele" (P8). Pai e mãe também destacaram sentimentos de apreensão por pensarem no filho durante todo o tempo que ele estava na creche: "Eu não conseguia parar de pensar um segundo nele (...). O que ele tava fazendo, se ele tava chorando, o que tava acontecendo, sabe" (M8). Frente a todos os aspectos mencionados, a decisão final foi a retirada do bebê da creche.

Outro bebê (B9/menina) que ingressou na creche aos 12 meses, apresentou semelhanças com o caso anterior no sentido de que também não permaneceu na creche, apesar de ter apresentado uma "ótima" adaptação. Segundo os genitores, a causa da recusa da filha manter-se na creche se deu devido aos desentendimentos do bebê mais antigo na turma com a filha que estava ingressando: "Era só ela e uma menina de um ano que tinha no berçário, então a menina de um ano já tava a um tempão no berçário e ela [filha] chegou depois e ai (...) não abriu muito espaço pra ela, e ai depois ela não quis mais ir de jeito nenhum que a gente fala em ir para escolinha ela fica desesperada" (M9). Mãe e pai destacaram que a filha ficou bem na creche e sem chorar durante as duas 
primeiras semanas de adaptação. As reações de choro, bem como de agarrar-se aos genitores, iniciaram após esse período quando o bebê começou a não mais querer ficar na creche. Tais aspectos do comportamento da filha fizeram com que mãe e pai ficassem em dúvida se ela estava sendo bem cuidada, já que, de repente, manifestou não querer mais ir à creche: " $A h$, a gente fica assim né, será que eles estão cuidando bem e tudo?" (M9). Frente a isso, a decisão final foi não levar mais a filha à creche, postergando a sua inserção na educação infantil para um momento em que ela tivesse melhores recursos de defesa: "Ai achamos melhor botar quando ela estiver falando. Pelo menos, se ela estiver falando, a gente pergunta, ela vai dizer 'olha, aconteceu isso, me bateram, me xingaram'" (P9).

Um padrão diferente de adaptação ocorreu com o bebê (B10/menina) que ingressou na creche aos 15 meses e apresentou uma boa adaptação, apesar do estranhamento inicial ao novo ambiente, manifestado através de choro e de isolamento: "No início ela chorava quando ia pra creche, no início ela não se misturava com as crianças, ela ficava sempre com a boneca dela" (M10). Frente a isso, a mãe relatou que, ao "sentir pena" em deixar a filha na creche, muitas vezes, saía chorando: "Eu ficava conversando com ela pra não fazer muito drama né, ai ela vinha e fazia beicinho, aí me cortava o coração" (M10). O pai também destacou que não era de seu desejo inserir a filha na creche, mas que as circunstâncias (trabalho da mãe) impuseram tal condição. Vale destacar que as maiores preocupações desses genitores referiram-se a mudanças comportamentais da filha após o período de um mês na creche. Eles destacaram terem observado que ela ficou mais agressiva com eles: "Às vezes um pouco de agressividade, às vezes ela te toca um brinquedo, coisas que ela não fazia" (M10).

Juntos, os relatos apresentados descrevem situações difíceis envolvendo a adaptação à creche durante a subfase de exploração do processo de separaçãoindividuação (Mahler, et al., 1977). As reações mais comuns dos bebês foram estranhamento frente ao ambiente da creche, choro, adoecimento, agarrar-se à mãe ou pai, recusa à alimentação e isolamento, o que de certa forma impossibilitava a exploração do novo ambiente e a interação com os demais. Vale destacar que predominou nos genitores sentimentos de insegurança em relação aos cuidados oferecidos na creche, o que pode ter influenciado a adaptação. Visto que os genitores podiam estar mais fragilizados emocionalmente, podem não ter conseguido servir de suporte emocional para o bebê. Nesse sentido, tendia a não ocorrer o "reabastecimento emocional" (Mahler, et al., 1977) necessário a fim de impulsionar o bebê na exploração e interação, de modo a facilitar a adaptação à creche.

\section{Subfase de reaproximação (17 a 24 meses)}

Nessa subfase do processo de separação-individuação (Mahler, et al., 1977), o bebê diminuiria um pouco o seu envolvimento com as habilidades motoras, e passaria a voltar a catexia novamente para a mãe ou outras figuras afetivas. Dessa forma, podese pensar que o bebê inserido na creche durante essa subfase poderá apresentar algumas particularidades em seu comportamento, como não querer ficar na creche sem a figura materna ou outra figura de referência, já que necessitaria de uma reaproximação com ela. Os casos apresentados a seguir, referentes a três bebês que ingressaram na creche durante a subfase de reaproximação, apresentam algumas evidências sobre essa subfase.

Um dos bebês (B11/menino), que ingressou na creche aos 21 meses, apresentou dificuldades durante a adaptação, já que inicialmente não queria ficar na creche, o que fez sua mãe pensar em desistir: "Eu ia desistir, porque eu não podia ficar toda a hora lá com ele" (M11). O choro surgiu como a principal reação dele frente à entrada na creche. Tal manifestação tornou a adaptação mais penosa para ele e seus genitores, já que a mãe esperava que o filho reagisse de forma melhor a esse momento. No entanto, pai e mãe destacaram que o filho acabou se adaptando à creche conseguindo, ao longo do tempo, ser acalmado pelas educadoras: "Eu largava ele lá e ele chorava bastante, ai depois a gente saía e ele ficava lá quietinho. Se adaptou bem" (P11). Vale destacar que sentimentos de preocupação e insegurança foram relatados particularmente pelo pai, já que, inicialmente, ele não se adaptou à ideia de deixar o filho com pessoas estranhas à família: "No começo eu não gostei muito, ia ficar com pessoas estranhas (...), já me preocupei bastante" (P11).

Outro bebê (B12/menina), que ingressou na creche aos 19 meses, frequentou uma creche por dois dias e, após esse período, a mãe não a levou mais, pois outra criança agrediu a filha que começou a manifestar medo de ficar na instituição. Já na segunda creche, onde ingressou alguns dias após, os genitores relataram que a adaptação ocorreu de forma mais tranquila. Para fins do presente estudo, será destacada a adaptação à segunda creche. Mais uma vez o choro surgiu como a principal reação do bebê no período de adaptação: “ $A$ primeira semana ela chorava, a semana inteirinha ela chorava" (M12). No entanto, com o passar dos dias, conseguiu ser acalmada alcançando uma adaptação satisfatória. O pai ressaltou sentimentos de insegurança quanto ao bem-estar da filha na creche, já que não era 
de seu desejo que ela fosse cuidada por pessoas fora do ambiente familiar: "O primeiro sentimento eu acho que é de insegurança né, que a gente está largando na mão de pessoas que a gente não sabe..." (P12). Já a mãe relatou sofrimento em deixar a filha na creche, o que a impedia de conseguir se despedir dela: "Daí eu botei ela no chão [quando deixou a filha na creche nos primeiros dias], ela foi pegar os brinquedinhos e eu virei as costas e sai"' (M12).

Referente ao outro bebê (B13/menina), que ingressou na creche aos 19 meses, a adaptação foi destacada como tranquila e se concretizando antes do período previsto. O choro apresentou-se como a reação da filha nos momentos iniciais de contato com a creche: "Chorava um pouco, mas ela gostou bastante, o primeiro dia que ela foi lá já nem queria vim, queria ficar brincando lá com as crianças" (P13). No entanto, os genitores relataram o fato de a filha ter recebido mordidas de um colega, o que fez o pai sentir vontade de não a levar mais à creche, situação que a mãe soube contornar: "O primeiro dia que ela foi pra creche ela veio mordida, dai o [marido] queria tirar ela da creche (...) só que dai eu falei pra ele que ia ser bom pra ela ficar na creche, né?" (M13). A mãe relatou que sentiu muita falta da filha em casa, chegando a lembrar de momentos com ela: "Super triste, desasada dentro de casa (...) eu chegava a lembrar das músicas que ela cantava e as palavras que ela falava" (M13).

Juntos, os relatos apresentados descrevem, predominantemente, que os bebês tiveram dificuldades em permanecer na creche, em um primeiro momento. $\mathrm{O}$ choro foi ressaltado como a principal reação dos bebês na subfase de reaproximação do processo de separaçãoindividuação (Mahler, et al., 1977). Às dificuldades iniciais de adaptação podem ser associadas, em certa medida, a não permanência de um dos genitores na creche para servir de suporte emocional para os bebês. No entanto, as educadoras conseguiram acalmá-los ao longo dos dias. Da mesma forma, os sentimentos de insegurança parentais foram sendo reduzidos ao ser destacado a importância da creche para a criança.

\section{DISCUSSÃO}

Frente aos dados apresentados constataram-se semelhanças e particularidades entre as reações dos bebês e os sentimentos parentais nas três subfases do processo de separação-individuação (Mahler, et al., 1977) investigadas. A maior parte dos bebês manifestou reações frente à entrada na creche, sendo choro calmo ou intenso, adoecimentos, recusa a alimentação, isolamento e agarrar-se à mãe ou pai quando entregue na creche.
Esses resultados estão na direção dos encontrados por Rapoport (1999) que investigou a adaptação de bebês à creche durante as dez primeiras semanas, com o objetivo de pesquisar as diferenças na adaptação em duas faixas etárias. Os resultados revelaram que os bebês utilizavam diferentes estratégias de enfrentamento para lidar com o estresse da adaptação, de acordo com a faixa etária em que ingressaram na creche, 4-5 meses e 7-8 meses. Os bebês menores tendiam a utilizar estratégias de enfrentamento corporal (ex. adoecimento), enquanto os maiores tendiam a utilizar estratégias focadas no problema (ex. agarrar-se à mãe). Estratégias focadas na emoção (ex. choro) foram utilizadas pelos bebês em ambas as faixas etárias, mas foram mais frequentes no grupo de bebês menores. Embora as idades investigadas por Rapoport correspondam à subfase de diferenciação dos bebês (Mahler, et al., 1977), algumas diferenças foram relatadas entre os bebês no início e no final do período examinado.

No presente estudo, as reações de recusa à alimentação e adoecimento foram destacadas com relação aos bebês que se encontravam nas subfases de diferenciação ( $6^{\circ}$ mês) e exploração (12ํำ mês). Já o choro foi mencionado como reação dos bebês em todas as subfases, no entanto foi a única reação destacada para os bebês que se encontravam na subfase de reaproximação $\left(20^{\circ}\right.$ mês). Isso permite pensar que com o desenvolvimento dos bebês, as estratégias de enfrentamento passam a ser menos voltadas para o corpo, e mais focadas na emoção (choro).

Pode-se ressaltar também que as reações dos bebês à entrada na creche afetavam, em certa medida, os sentimentos parentais, da mesma forma que estes pareceram influenciar as reações manifestas pela criança (Vitória \& Rossetti-Ferreira, 1993). Sem dúvida contribui para isto os sentimentos maternos frente à entrada do bebê na creche investigados por Ferreira (2007). A autora destacou que os sentimentos mais comuns foram preocupação e desconfiança frente aos cuidados que as educadoras dispensavam aos bebês, e sentimentos ambivalentes, já que as mães também destacaram a creche como importante para o desenvolvimento dos filhos.

No presente estudo, sentimentos de sofrimento, insegurança e tranquilidade frente à entrada do filho na creche foram destacados pelos genitores em todas as subfases. Os sentimentos de insegurança e sofrimento estavam relacionados às reações do próprio bebê (chorar, recusar a alimentação, adoecer), ao não saber como o filho seria cuidado na creche e às desconfianças frente aos cuidados oferecidos pelas educadoras. E também, ao desejo de não inserir o bebê em um cuidado alternativo, e por perceberem que o bebê ficava bem sem 
o pai e a mãe destacando, assim, reações mais difíceis para os genitores do que para o próprio bebê. Já os sentimentos de tranquilidade estavam relacionados, principalmente, ao fato de a creche ser um espaço adequado para os cuidados infantis. Vale destacar que esses sentimentos de tranquilidade se fizeram mais presentes entre os genitores dos bebês que se encontravam na subfase de diferenciação (6ํำ mês), já que para eles a creche era um espaço adequado principalmente por ter mais de uma educadora disponível, o que, assim, evitaria a sobrecarga dos cuidados em apenas uma pessoa.

Já os sentimentos de insegurança e sofrimento fizeram-se presentes em todas as subfases investigadas, sendo que na subfase de diferenciação ( $6^{\circ}$ mês) e reaproximação ( $20^{\circ}$ mês) tais sentimentos pareceram influenciar a adaptação do bebê à creche, embora de maneira menos expressiva na subfase de reaproximação. Isso tudo porque em alguns casos as mães e/ou pais vivenciaram intenso sofrimento frente à inserção do bebê à creche e acabaram fragilizados o que, de certa maneira, os impediu de servirem como suporte emocional para eles (Mahler, et al., 1977), no momento de adaptação à creche. Já na subfase de exploração (12ํㅡês) os sentimentos de insegurança dos genitores apareceram de forma mais intensa, quando comparado às outras subfases, o que pode ter contribuído para as dificuldades que culminaram no fracasso da adaptação, em alguns casos. Tais aspectos permitem perceber que a adaptação à creche pode ser um processo extremamente complexo para alguns bebês, mães e pais, por envolver não somente o mundo subjetivo do bebê, mas também de seus genitores (Amorim, et al., 2000; Rapoport \& Piccinini, 2004). Os sentimentos destacados pelas mães e pais do presente estudo parecem remeter, em certa medida, ao próprio processo de separação-individuação dos genitores (Colarusso, 1990; Mahler, et al., 1977). No momento da constituição da parentalidade e ao longo do desenvolvimento do bebê são ativados resquícios conscientes ou inconscientes desse processo vivido pelos próprios pais quando crianças, que podem afetar a relação mãe-pai-bebê e, como destacou o presente estudo, a adaptação do bebê e dos genitores à entrada na creche.

Aspecto importante de ser destacado refere-se ao fato de que para a maior parte dos bebês que ingressaram na creche durante a subfase de diferenciação ( $6^{\circ}$ mês), o processo de adaptação se deu com a presença de um familiar do bebê na creche, tendo assumido a adaptação aquele genitor que se mostrou menos fragilizado emocionalmente nesse momento. A presença de uma figura de referência para o bebê permite a ele ter confiança no novo ambiente, possibilitando uma separação menos traumática em relação à mãe e ao pai (Mahler, et al., 1977) e permitindo que as educadoras tornem-se, progressivamente, as figuras de referência no novo ambiente. Já durante a subfase de exploração (12ํำ mês) e reaproximação ( $20^{\circ}$ mês) a adaptação à creche tendeu a ocorrer, em vários casos, sem a presença de um familiar. Tal fato permite pensar que o bebê, durante a subfase de exploração (12ํำ mês), tem capacidade motora de explorar o ambiente ao redor, no entanto, de tempos em tempos necessita retornar até a figura materna ou paterna para realizar o "reabastecimento emocional", através do contato físico com ela (Mahler, et al., 1977). Tal comportamento permite ao bebê confiar no novo ambiente de interação, por perceber que tem a quem retornar caso sofra alguma frustração até que as próprias educadoras tenham capacidade de oferecer o reabastecimento emocional que o bebê necessita. $\mathrm{O}$ mesmo ocorreria na subfase de reaproximação ( $20^{\circ}$ mês), em que a presença ativa da mãe ou outra figura afetiva faz-se importante para o reabastecimento emocional, para acalmar a criança (Mahler, et al., 1977). No entanto, a não permanência de um dos genitores na creche, neste último caso, não pareceu essencial pelo menos para um dos casos investigados no presente estudo. Apesar disso, vale ressaltar que a presença de um dos genitores na creche é considerada na literatura como importante para uma adaptação satisfatória, independente da faixa etária do bebê e criança pequena. Rapoport e Piccinini (2001) em seu estudo com 41 educadoras que atendiam bebês entre 4-5 meses e 8-9 meses destacaram que a presença da mãe ou pai no momento de adaptação e os horários reduzidos de permanência do bebê nos primeiros dias são importantes para que a creche torne-se uma referência para o bebê e, assim, se adapte de forma satisfatória.

Antes de finalizar, vale ressaltar algumas limitações do presente estudo. Em primeiro lugar, o fato de as entrevistas não terem sido realizadas no momento em que ocorria a adaptação dos bebês à creche pode não ter permitido captar, de maneira expressiva, os sentimentos e reações das mães, dos pais e dos bebês. Sugere-se para próximos estudos, que o contato com os genitores ocorra antes mesmo da entrada na creche, no momento em que se realiza a matrícula, o que permitirá acessar os sentimentos que envolvem a inserção do bebê na creche, seja com relação à decisão de colocá-lo na creche, até a inserção de modo efetivo. No entanto, não se pode negar que a realização das entrevistas em um momento posterior a entrada do bebê na creche também pode trazer informações importantes, ao permitir aos genitores trazerem conteúdos que não seriam, talvez, 
revelados no momento em que estivessem vivenciando as situações mais difíceis. Vale ressaltar também que as creches em que os bebês foram inseridos possuíam diferentes configurações, e que não se teve acesso a dados sobre a qualidade dessas creches, bem como sobre a dinâmica utilizada no momento da adaptação do bebê à educação infantil. Esses dados permitiriam entender os sentimentos e reações parentais e dos bebês a esse momento de adaptação, e o quanto a creche se constituía em um contexto de desenvolvimento adequado contribuindo para tranquilizar os genitores. Assim, sugere-se, para próximos estudos, que se tenham informações sobre a própria creche, seja através das educadoras e gestoras, seja através da perspectiva dos genitores, o que contribuiria para sanar a limitação destacada.

\section{CONSIDERAÇÕES FINAIS}

O presente estudo investigou os relatos das mães e pais sobre a adaptação de bebês à creche em diferentes faixas etárias de acordo com as subfases do processo de separação-individuação: diferenciação, exploração e reaproximação (Mahler, et al., 1977). As reações dos bebês e os sentimentos parentais foram investigados, permitindo destacar semelhanças e particularidades entre cada subfase investigada. A teoria sobre o processo de separação-individuação (Mahler, et al., 1977) foi originalmente elaborada a partir do estudo de bebês cuidados por suas mães. No presente estudo, o foco foi à entrada do bebê na creche, permitindo que se tenham evidências sobre a teoria em outro contexto de desenvolvimento infantil. Os resultados revelaram que, independente da subfase investigada, a separação real mãe-pai-bebê ocorreu de modo menos traumático quando contava com a presença de um dos genitores na creche, servindo de suporte emocional para o bebê durante esse período de transição. Tal aspecto contribuiu, em certa medida, para que a creche se tornasse uma referência para o bebê facilitando a continuidade de seu processo de separação-individuação, mesmo distante da figura materna ou outra figura afetiva. No entanto, vale ressaltar a importância de a figura afetiva não estar fragilizada emocionalmente durante esse momento, o que tende a prejudicar a adaptação do bebê à creche. Tal aspecto permite pensar na importância de se considerar todos os envolvidos nesse momento de adaptação, não se centrando somente no bebê, mas também em sua mãe, pai e educadoras. Nesse sentido, intervenções no contexto da creche, envolvendo a própria família, podem ser pensadas, de modo a auxiliar todos os envolvidos na adaptação do bebê.

\section{REFERÊNCIAS}

Ahnert, L., Gunnar, M. R., Lamb, M. E., \& Barthel, M. (2004). Transition to child care: Associations with infant-mother attachment, infant negative emotion, and cortisol elevations. Child Development, 75(3), 639-650.

Albers, E. M., Riksen-Walraven, M., \& Weerth, C. (2010). Developmental stimulation in child care centers contributes to young infants' cognitive development. Infant Behavior, \& Development, (33), 401-408. doi: 10.1016/j.infbeh.2010.04.004

Amorim, K. S., Vitoria, T., \& Rossetti-Ferreira, M. C. (2000). Rede de significações: perspectiva para análise da inserção de bebês na creche. Cadernos de Pesquisa, (109), 115-144.

Baltieri, L., Santos, D. C. C., Gibim, N. C., Souza, C. T., Batistela, A.C.T., \& Tolocka, R.E. (2010). Desempenho motor de lactentes frequentadores de berçários em creches públicas. Revista Paulista de Pediatria, 28(3), 283-289.

Bardin, L. (1977). Análise de Conteúdo. Edições 70 LDA.

Brasil. (1998). Ministério de Educação e do Desporto. Referencial curricular nacional para educação infantil. Brasília, DF: MEC.

Colarusso, C. A. (1990). The third individuation: The effect of biological parenthood on separation-individuation processes in adulthood. Psychoanalitical Study of the Child, 45, 179-194.

Davies, J., \& Brember, I. (1991). Attendance period on children's adjustment to nursery classes. British Educational Research Journal, 17(1), 73-83.

Dias, I. S. (2010). A relação educadora-bebê: laços possíveis (Dissertação de mestrado). Programa de Pós-graduação em Educação, Universidade Federal do Rio Grande do Sul, Porto Alegre.

Erikson, E. (1972). Identidade, juventude e crise. Rio de Janeiro: Zahar Editores. (Original publicado em 1968).

Ferreira, G. V. (2007). O impacto da adaptação de crianças na creche sobre os sentimentos maternos (Monografia de especialização). Programa de Especialização em Psicologia Clínica, Universidade Federal do Rio Grande do Sul, Porto Alegre.

Gabriel, M. R. (2012). Transformações no envolvimento paterno ao longo dos seis primeiros meses do bebê na creche (Dissertação de mestrado). Programa de Pós-graduação em Psicologia, Universidade Federal do Rio Grande do Sul, Porto Alegre.

Grupo de Interação Social, Desenvolvimento e Psicopatologia GIDEP/UFRGS/CNPQ (1998a). Entrevista sobre a experiência da maternidade e desenvolvimento do bebê. Instituto de Psicologia, Universidade Federal do Rio Grande do Sul. (Instrumento não publicado).

Grupo de Interação Social, Desenvolvimento e Psicopatologia GIDEP/UFRGS/CNPQ (1998b). Entrevista sobre a experiência da paternidade e desenvolvimento do bebê. Instituto de Psicologia, Universidade Federal do Rio Grande do Sul. (Instrumento não publicado).

Grupo de Interação Social, Desenvolvimento e Psicopatologia GIDEP/UFRGS/CNPQ (1998c). Ficha de dados demográficos da família. Instituto de Psicologia, Universidade Federal do Rio Grande do Sul. (Instrumento não publicado).

Laville, C., \& Dionne, J. (1999). A construção do saber: manual de metodologia da pesquisa em ciências humanas. Porto Alegre: Artmed.

Lordelo, E. R., Chalhub, A. A., Guirra, R. C., \& Carvalho, C. S. (2007). Contexto e desenvolvimento cognitivo: frequência à creche e evolução do desenvolvimento mental. Psicologia: Reflexão e Crítica, 20(2), 324-334. 
Mahler, M., Pine, F., \& Bergman, A. (1977). O nascimento psicológico da criança. Rio de Janeiro: Zahar Editores. (Original publicado em 1975).

Majorano, M., Cigala, A., \& Corsano, P. (2009). Adults' and Children's Language in Different Situational Contexts in Italian Nursery and Infant Schools. Child Care in Practice, 15(4), 279297. doi: 10.1080/13575270903149349

Maranhão, D. G., \& Sarti, C. A. (2007). Cuidado compartilhado: negociações entre famílias e profissionais em uma creche. Interface: Comunicação, Saúde, Educação, 11(22), 257-270.

Maranhão, D. G., \& Sarti, C. A. (2008). Creche e família: uma parceria necessária. Cadernos de Pesquisa, 38(133), 171-194.

Mariotto, R. M. M. (2009). Cuidar, educar e prevenir: as funções da creche na subjetivação de bebês. São Paulo. Escuta.

Murta, A. M. G., Lessa, A. C., Santos, A. S., Murta, N. M. G., \& Cambraia, R. P. (2011). Cognição, motricidade, autocuidados, linguagem e socialização no desenvolvimento de crianças em creche. Revista Brasileira de Crescimento e Desenvolvimento Humano, 21(2), 220-229.

Piccinini, C. A., Tudge, J., Lopes, R. C. S., \& Sperb, T. (1998). Estudo longitudinal de Porto Alegre: da gestação à escola. Projeto de Pesquisa, Instituto de Psicologia, Universidade Federal do Rio Grande do Sul. (Projeto não publicado).

Ramos, D. D. (2010). Interação adulto-criança em creches públicas: estilos linguísticos. (Dissertação de mestrado). Departamento de Pós-graduação em Psicologia Social, Universidade Federal da Paraíba, João Pessoa.

Rapoport, A. (1999). Adaptação de bebês à creche: o ingresso no primeiro ou segundo semestre de vida (Dissertação de mestrado). Programa de Pós-Graduação em Psicologia, Universidade Federal do Rio Grande do Sul, Porto Alegre.

Rapoport, A., \& Piccinini, C. A. (2001). Concepções de educadoras sobre a adaptação de bebês à creche. Psicologia: Teoria e Pesquisa, 17(1), 69-78.
Rapoport, A., \& Piccinini, C. A. (2004). A escolha do cuidado alternativo para o bebê e a criança pequena. Estudos de Psicologia, 9(3), 497-503.

Santos, F. M. S., \& Moura, M. L. S. (2002). A relação mãe-bebê e o processo de entrada na creche: esboços de uma perspectiva sociocultural. Psicologia: ciência e profissão, 22(2), 88-97.

Schmitt, R. V. (2008). “Mas eu não falo a língua deles!”: as relações sociais de bebês num contexto de educação infantil. (Dissertação de mestrado). Programa de Pós-Graduação em Educação, Universidade Federal de Santa Catarina, Florianópolis.

Sestini, A. E. (2008). Interação social e comunicação na primeira infância. (Tese de doutorado). Programa de Pós-graduação em Psicologia, Universidade de São Paulo, São Paulo.

Stake, R. E. (1994). Case studies. In N. K. Denzin, \& Y. S. Lincoln (Eds.). Handbook of qualitative research. New York: Sage Publications.

Vitória, T., \& Rossetti-Ferreira, M. C. (1993). Processos de adaptação na creche. Cadernos de Pesquisa, 86, 55-64.

Autores:

Tatiele Jacques Bossi - Doutoranda do Programa de Pós-Graduação em Psicologia, Universidade Federal do Rio Grande do Sul.

Elenice Soares - Psicóloga graduada pela Universidade Federal do Rio Grande do Sul.

Rita de Cássia Sobreira Lopes - Professora do Programa de Pós-Graduação em Psicologia, Universidade Federal do Rio Grande do Sul.

Cesar Augusto Piccinini - Professor do Programa de Pós-Graduação em Psicologia, Universidade Federal do Rio Grande do Sul.

\section{Endereço para correspondência:}

Tatiele Jacques Bossi

Rua Ramiro Barcelos, 2600, sala 111

CEP 90035-003 Porto Alegre, RS, Brasil

E-mail: tatielejbossi@gmail.com

Recebido em: 16.12 .2013

Aceito em: 20.06.2014 